\title{
Effects of Heart Rate vs. Speed-Based High Intensity Interval Training on Aerobic and Anaerobic Capacity of Female Soccer Players
}

\author{
Hamid Arazi ${ }^{1, *}$, Abbas Keihaniyan ${ }^{1}$, Amin EatemadyBoroujeni ${ }^{2}$, Amir Oftade ${ }^{3}$, \\ Sheida Takhsha ${ }^{4}$, Abbas Asadi ${ }^{1,5}$ and Rodrigo Ramirez-Campillo ${ }^{6}$ \\ 1 Department of Exercise Physiology, Faculty of Sport Sciences, University of Guilan, Rasht 1438, Iran; \\ abbas.keihaniyan@yahoo.com (A.K.); Abbas_asadi1175@yahoo.com (A.A.) \\ 2 Department of Exercise Physiology, Faculty of Sport Sciences, University of Isfahan, Isfahan 81746, Iran; \\ eatemady@gmail.com \\ 3 Department of Exercise Physiology, Faculty of Sport Sciences, University of Shahid Beheshti; \\ Tehran 19834, Iran; Amiroftade@yahoo.com \\ 4 Department of Exercise Physiology, Faculty of Sport Sciences, Isfahan Islamic Azad University, \\ Khorasgan Branch, Khorasgan 81595-158, Iran; sheida.takhsha@yahoo.com \\ 5 Roudbar Branch, Islamic Azad University, Roudbar, 446161-4579, Iran \\ 6 Department of Physical Activity Sciences, Research Nucleus in Health, Physical Activity and Sport, \\ Universidad de Los Lagos, Osorno 5290000, Chile; r.ramirez@ulagos.cl \\ * Correspondence: hamidarazi@yahoo.com; Tel.: +98-911-139-9207; Fax: +98-133-369-0675
}

Received: 13 May 2017; Accepted: 21 July 2017; Published: 4 August 2017

\begin{abstract}
The purpose of this study was to compare the effects of two types of high-intensity interval training (HIIT) programs on aerobic and anaerobic capacity of female soccer players. Regional-level female athletes were randomly divided into heart rate-based HIIT $(n=8$; age $23.4 \pm 1.1$ year) and speed-based HIIT groups ( $n=8$; age $23.4 \pm 1.3$ year). Athletes trained three days per week for six weeks. Before and after training, each athlete's performance was assessed directly through the Hoff test, 30-15 Intermittent Fitness Test (VIFT), and repeated-sprint ability test (RAST); maximal oxygen consumption $\left(\mathrm{VO}_{2} \mathrm{max}\right)$, power and fatigue were estimated indirectly. Both experimental groups improved power, fatigue index and $\mathrm{VO}_{2}$ max after training $(p<0.05)$. It was noteworthy that the speed-based group had greater gains in minimal power (effect size (ES): 3.99 vs. 0.75), average power (ES: 2.23 vs. 0.33 ), and fatigue index (ES: 2.53 vs. 0.17$)$ compared to heart rate-based group $(p<0.05)$. In conclusion, both heart rate-based and speed-based HIIT induced meaningful improvements in power, $\mathrm{VO}_{2} \mathrm{max}$, and fatigue index in female soccer players, although the speed-based HIIT group achieved greater gains in power and fatigue index compared to the heart rate-based group.
\end{abstract}

Keywords: VIFT; women; football; power

\section{Introduction}

Soccer is an intermittent sport that requires different physiological components [1,2]. The dominant energy system in soccer is the aerobic system, with soccer players covering up to 12 kilometers per game [3-5] at $\sim 75 \%$ of $\mathrm{VO}_{2}$ max [2,6]. It has been reported that improvements in aerobic capacity (i.e., $\mathrm{VO}_{2}$ max, running economy and lactate threshold) are in line with increases in players' physical fitness, technique and tactical performance [1,7]. Moreover, the capacity to produce varied powerful actions during a 90-min game is associated with high aerobic capacity [1,2]. In addition to aerobic capacity, several short-duration and maximal-intensity movements in soccer depends on anaerobic capacity, were athletes perform 1000 to 1400 of such movements during a game $[3,4]$. Therefore, anaerobic and aerobic capacities maybe critical to soccer performance. 
An effective training method to improve these variables is high-intensity interval training (HIIT), with positive effects on both aerobic and anaerobic fitness [8]. The literature, particularly with reference to high-intensity interval training (HIIT), has recently been reviewed [9]. Since one of the chief barriers to broad public participation in exercise programs is a perceived lack of time [10], one of the appeals of HIIT training has been that it potentially represents a more time-efficient way of accomplishing the adaptive goals of exercise training. HIIT may improve soccer players' $\mathrm{VO}_{2} \max [1,8,11]$, power $[11,12]$, fatigue resistance [13], stroke volume [14], oxidative and glycolytic enzyme activities [11], lactate tolerance $[15,16]$, motor efficiency and lactate utilization [1], with reduced exercise time requirements. However, optimum HIIT design is elusive, especially regarding intensity prescription [2] and practical strategies to control it.

Prescription of HIIT based on heart rate (HR) or running speed are common ways to control the intensity for soccer players.

Speed-based training, or maximal running velocity (VIFT) training, is a graded intermittent and shuttle field training. The use of VIFT has been shown to be more accurate than individual $\mathrm{VO}_{2} \mathrm{max}$ (i.e., the lowest running velocity that elicits maximal oxygen uptake during a continuous graded test) for getting players with different physiological profiles to a similar level of cardiorespiratory demand and, thus, for standardizing training content at a team level [8]. In contrast, HR-based training (i.e., Hoff method) proposed a specific circuit with jumps, running backwards and changing directions whilst dribbling the ball, which has been shown to be related to match performance [8]. This circuit is also useful to determine maximal oxygen consumption [11] and maximal heart rate (HRmax) [11], but the maximum distance covered in the Hoff circuit is not correlated with aerobic endurance determined on the treadmill [16]. Use of HR (i.e., Hoff method), although probably the most commonly used method to prescribe the intensity for HIIT, is limited by the athlete's psychological status and ability to regulate running intensity, and HR is usually poorly associated with metabolic demands [17]. Alternatively, speed-based HIIT prescriptions (i.e., 30-15 Intermittent Fitness Test) are also common, and have been shown to be relevant for players with different fitness levels [18].

Moreover, investigating the effects of these methods on enhancing physiological variables in female soccer players is paramount. Exercise training in female players may improve their maximal-intensity exercise and endurance. However, further investigation in this population is required, especially with regard to factors that might be mediating the effects of HIIT on aerobic and anaerobic capacity adaptations. To our knowledge, there are no previous studies that have examined the influence of HR vs. speed-based HIIT training on physiological adaptations in female soccer players. To help clarify practical strategies for optimal intensity prescription, the purpose of this study was to compare the effects of HR-based and speed-based intensity sessions for HIIT on aerobic and anaerobic capacity of female soccer players.

\section{Materials and Methods}

\subsection{Study Design}

Female soccer players participated in the study and were randomly divided into two HIIT groups with different intensity prescription methods: HR-based and speed-based. Before and after six weeks of training, athletes performed the Hoff, 30-15 Intermittent Fitness Test (VIFT), and RAST tests to determine the effects of HIT training on aerobic and anaerobic capacities of female soccer players. Both HR-based and speed-based training sessions were performed at the same time of day (i.e., morning).

\subsection{Participants}

Sixteen healthy female soccer players from a semi-professional soccer academy with similar training habits and loads volunteered to participate in this study, and were randomly divided into two training groups (Table 1). In order to ensure no subjects had any orthopedic or health related conditions that could preclude them from participating in training and measurements, all subjects underwent a 
supervised screening undertaken by a physician. Exclusion criteria included subjects with potential medical problems; subjects with a history of ankle, knee, or back pathology in the three months before the study; subjects with medical or orthopedic problems that compromised their participation or performance; subjects who had had any lower extremity reconstructive surgery in the past two years; and subjects with unresolved musculoskeletal disorders or a pregnancy period. The study was conducted in accordance with the Institutional Ethics Review Committee from the University.

Table 1. Subject characteristics.

\begin{tabular}{ccc}
\hline Characteristics & HR-Based $(\boldsymbol{n}=\mathbf{8})$ & Speed-Based $(\boldsymbol{n}=\mathbf{8})$ \\
\hline Age (years) & $22.4 \pm 1.1$ & $22.4 \pm 1.3$ \\
Weight $(\mathrm{kg})$ & $59.1 \pm 1.3$ & $55.9 \pm 2.3$ \\
Height $(\mathrm{cm})$ & $170.9 \pm 2.6$ & $165.1 \pm 3.2$ \\
$\mathrm{BMI}\left(\mathrm{kg} \cdot \mathrm{m}^{-2}\right)$ & $20.3 \pm 0.8$ & $20.6 \pm 0.9$ \\
$\mathrm{VO}_{2} \mathrm{max}\left(\mathrm{mL} \cdot \mathrm{kg}^{-1} \cdot \mathrm{min}^{-1}\right)$ & $50.3 \pm 1.8$ & $50.6 \pm 2.2$ \\
Soccer experience (years) & $10.1 \pm 2.8$ & $10.3 \pm 3.1$ \\
Weekly soccer training (time, hour) & $4.5 \pm 0.2$ & $4.5 \pm 0.3$ \\
\hline
\end{tabular}

Values are mean \pm SD.

\subsection{Testing Procedures}

All tests were performed one week before and after 6 weeks of HIIT in the morning (i.e., 9 to 11 a.m.). Before testing, subjects performed a 10-min general warm-up protocol consisting of sub-maximal running (i.e., 5-min), active stretching (i.e., 5-min), and three submaximal vertical jumps. Prior to each test, the players performed 2-3 submaximal trials for familiarization.

\subsubsection{Hoff Test}

The procedure of this test is described in detail elsewhere [19]. Briefly, according to Figure 1, from the start point, players dribbled through the first 10 cones, then jumped three $30-\mathrm{cm}$ height cones, then dribbled through 8 cones as fast as possible toward point $A$. Athletes then run backwards from point $A$ to point $B$, and after point $B$ players run forward again to the starting point. Each athlete has $10 \mathrm{~min}$ to complete as many laps as possible. Total distance $(\mathrm{m})$ and estimated $\mathrm{VO}_{2}$ max were measured as markers of specific endurance of soccer players, regarding previously described $[19,20]$. Players are to dribble the ball during the test. During the test, subjects were encouraged to perform at maximal effort. 


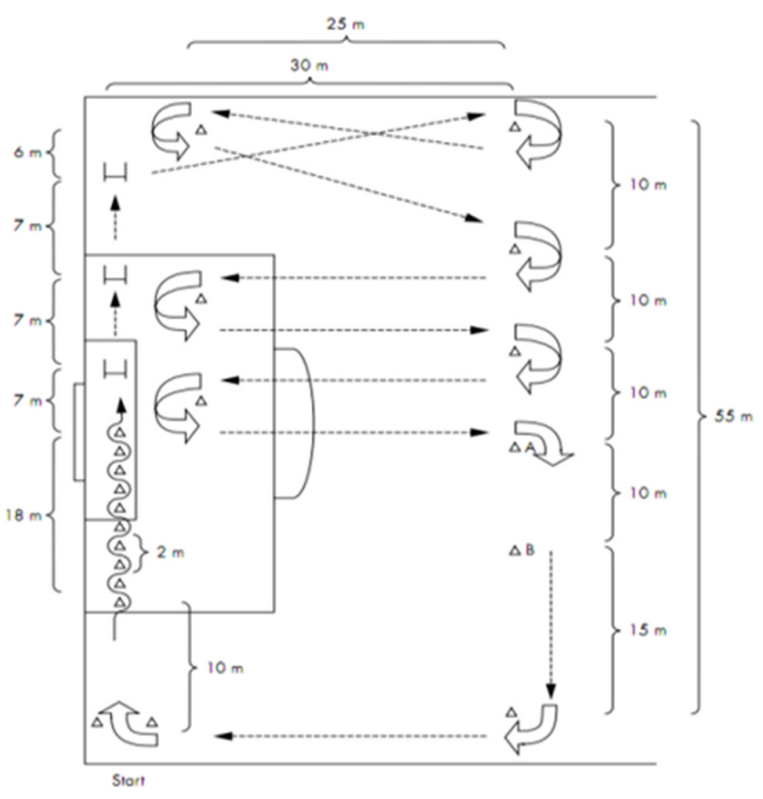

Figure 1. Hoff test (details in text).

\subsection{2. $\mathrm{V}_{\mathrm{IFT}}$ Test}

Buchheit [21] described the VIFT previously. Briefly, this test consists of 30-s shuttle runs interspersed with 15-s passive recovery periods. Velocity was set at $8 \mathrm{~km} / \mathrm{h}$ for the first 30 -s run and was increased by $0.5 \mathrm{~km} / \mathrm{h}$ every 45 -s stage thereafter. Calculation of targeted distances to run during each 30-s period took into account the fact that the effort to turn is increased when running speed is increased. An empirical value of $0.7 \mathrm{~s}$ was subtracted from the 30-s running periods for each change of direction. For example, at $11.5 \mathrm{~km} / \mathrm{h}$, one would cover $96 \mathrm{~m}$ in a 30-s straight line run, but covering the same distance over a 40-m shuttle distance requires two changes of direction taking up to $0.7 \mathrm{~s}$, which brings the corrected distance run to $91.6-\mathrm{m}$. The subjects had to run back and forth between two lines set 40-m apart at a pace governed by a pre-recorded beep at appropriate intervals that helped them adjust their running speed by entering into 3-m zones at each end of the running area and in the middle of the area, while the short beep sounds. During the 15-s recovery period, the subjects walked in the forward direction to join the closest line (at the middle or at one end of the running area, depending on where the previous run stopped) from where they started the next run stage. Performance in this test was expressed as estimated $\mathrm{VO}_{2} \max \left(\mathrm{mL} \cdot \mathrm{kg}^{-1} \cdot \mathrm{min}^{-1}\right)$, speed $\left(\mathrm{km} \cdot \mathrm{h}^{-1}\right)$ and time (min). During the test, subjects were orally encouraged to perform at maximal effort [18].

$$
\begin{aligned}
\mathrm{VO}_{2 \max }= & 28.3-2.15 \times \operatorname{Sex}(\text { Male }=1, \text { Female }=2)-0.741(\text { Age })-0.357(\text { Weight }) \\
& +0.0586(\text { Age })(\text { VIFT }[\text { speed, } \mathrm{km} / \mathrm{h}])+1.03(\text { VIFT }[\text { speed }, \mathrm{km} / \mathrm{h}])
\end{aligned}
$$

\subsubsection{RAST Test}

This test was used to measure athletes' anaerobic performance ability, including minimum, maximum and average power, and fatigue index. Athletes run 35-m intervals, six times, with $10 \mathrm{~s}$ of rest between each interval. Power and fatigue index were calculated as previously suggested [21]. To estimate power $(\mathrm{W})$ and fatigue index $(\mathrm{W} / \mathrm{s})$, a previously established equations (power $=\frac{\text { weight } \times \text { distance } 2}{\text { time } 3}$, fatigue index $=\frac{\text { maximal power }- \text { minimal power }}{\text { total time of six repetitions }}$ ) were used.

\subsection{Training Program}

Athletes performed regular soccer practices three days per week for 60-70 min on Sunday, Thursday and Friday, and participated in their HIIT programs three days per week (Saturday, Monday, 
and Wednesday) which added to their regular training load. All subjects in the present study were required to complete all training sessions. A trained researcher monitored training sessions in order to ensure that all exercises were performed correctly with the appropriate rest intervals.

\subsubsection{HR-Based HIIT Protocol}

Athletes run at $90 \%$ of maximal HR for $90 \mathrm{~s}$ and then walk for $90 \mathrm{~s}$, with the pattern repeated during $7.5 \mathrm{~min}$. Then athletes rested passively for $2 \mathrm{~min}$. This sequence was repeated three times, for twelve 90-s runs per session. HR was recorded during training sessions (Heart rate monitor, Acentas pulse meter, BM-CS5EU, Beijing, China). Regarding the principle of overload, although not controlled, over time it was perceived that athletes ran longer distances while maintaining $90 \%$ of maximal HR for $90 \mathrm{~s}$.

\subsubsection{Speed-Based HIIT Protocol}

After determining maximal speed during the VIFT test, $90 \%$ of the maximal speed and traveled distance for each athlete was selected. Players had to get to the cone with every beep (beep speed was designed based on $10 \mathrm{~km} / \mathrm{h}$ ). Athletes run at this speed for $90 \mathrm{~s}$, and then walk for $90 \mathrm{~s}$. This activity-recovery pattern was repeated for $7.5 \mathrm{~min}$, with passive rest for $2 \mathrm{~min}$. This sequence was repeated two times. Regarding the principle of overload, the velocity increased $5 \%$ every two weeks [20].

\subsection{Statistical Analysis}

IBM SPSS version 22 software was used to analyze the data. Normality of the collected data was evaluated by the Shapiro-Wilk test after the verification of data normality, $2 \times 2$ ANOVA was used to determine the effects of training on dependent variables. The magnitude of the effect size statistics was considered trivial $<0.2$; small, $0.2-0.49$; moderate, $0.5-0.79$; large, $0.8-1.3$; very large $>1.30$ [22]. The effect size is reported in conjunction with the $95 \%$ confidence limits (CI) for all analyzed measures. The level of significance was set at $p \leq 0.05$. The statistical tests were performed using the SPSS statistical package version 16 (Chicago, IL, USA).

\section{Results}

There were no significant differences between the groups at pre-training. No significant groupings by time interaction were observed after HIIT for the maximal power $(\mathrm{F}=0.009, \mathrm{P}=0.653)$, Hoff test traveled distance $(\mathrm{F}=0.08, \mathrm{P}=0.43), \mathrm{VO}_{2 \max }$ in Hoff $(\mathrm{F}=0.11, \mathrm{P}=0.88)$, VIFT $(\mathrm{F}=0.93, \mathrm{P}=0.13)$, VIFT speed $(\mathrm{F}=0.319, \mathrm{P}=0.586)$ and time $(\mathrm{F}=1.1, \mathrm{P}=0.7)$ tests. After 6-week HIIT, the speed-based group indicated greater gains in minimal power $(\mathrm{F}=5.08, \mathrm{P}=0.04)$, average power $(\mathrm{F}=32.12, \mathrm{P}=0.003)$, and fatigue index $(\mathrm{F}=28.32, \mathrm{P}=0.002)$ compared with the HR-based group (Table 2).

Table 2. Changes in aerobic and anaerobic capacity for the HR-based $(n=8)$ and speed-based HIIT groups $(n=8)$. Values are reported as mean $\pm \mathrm{SD}$.

\begin{tabular}{ccccc}
\hline Variables & Before & After & Effect Size & Confidence Limits (CI) \\
\hline Maximal Power (Watts) & & & \\
\hline HR-based & $562 \pm 32.9$ & $572 \pm 35.6$ & 0.29 & 1.25 to -0.71 \\
Speed-based & $568 \pm 21.4$ & $579 \pm 23.3$ & 0.1 & 1.07 to -0.89 \\
\hline Minimal Power (Watts) & & & \\
\hline HR-based & $289 \pm 17.3$ & $302 \pm 15.6^{*}$ & 0.75 & 1.72 to -0.3 \\
Speed-based & $309 \pm 13.0$ & $366 \pm 15.3^{*,+}$ & 3.99 & 5.41 to 2.14 \\
\hline Average Power (Watts) & & & \\
\hline HR-based & $425 \pm 21.5$ & $432 \pm 20.3$ & 0.33 & 1.29 to -0.68 \\
Speed-based & $430 \pm 13.8$ & $464 \pm 16.8^{*,+}$ & 2.23 & 3.33 to 0.88 \\
\hline
\end{tabular}


Table 2. Cont.

\begin{tabular}{|c|c|c|c|c|}
\hline Variables & Before & After & Effect Size & Confidence Limits (CI) \\
\hline \multicolumn{5}{|c|}{ Fatigue index $(\mathrm{W} / \mathrm{s})$} \\
\hline HR-based & $8.3 \pm 0.8$ & $8.1 \pm 0.8$ & 0.17 & 1.14 to -0.82 \\
\hline Speed-based & $8.0 \pm 0.5$ & $6.7 \pm 0.5^{*,+}$ & 2.53 & 3.67 to 1.11 \\
\hline \multicolumn{5}{|c|}{$\begin{array}{l}\text { Hoff test traveled } \\
\text { distance }(\mathrm{m})\end{array}$} \\
\hline HR-based & $1308 \pm 120$ & $1630 \pm 234^{*}$ & 1.37 & 2.77 to -0.51 \\
\hline Speed-based & $1311 \pm 139$ & $1468 \pm 165^{*}$ & 1.02 & $2.50-0.07$ \\
\hline \multicolumn{5}{|c|}{$\begin{array}{l}\mathrm{VO}_{2} \max \text { in Hoff test } \\
\left(\mathrm{mL} \cdot \mathrm{kg}^{-1} \cdot \mathrm{min}^{-1}\right)\end{array}$} \\
\hline HR-based & $48.6 \pm 6.2$ & $54.8 \pm 10.6^{*}$ & 0.71 & 1.67 to -0.34 \\
\hline $\mathrm{V}_{\mathrm{IFT}}$ & $49.2 \pm 4.1$ & $53.6 \pm 11.6^{*}$ & 0.51 & 1.47 to -0.52 \\
\hline \multicolumn{5}{|c|}{$\begin{array}{l}\mathrm{VO}_{2} \max \text { in } \mathrm{V}_{\mathrm{IFT}} \text { test } \\
\left(\mathrm{mL} \cdot \mathrm{kg}^{-1} \cdot \mathrm{min}^{-1}\right)\end{array}$} \\
\hline HR-based & $50.6 \pm 7.7$ & $53.6 \pm 8.2 *$ & 0.38 & 1.34 to -0.63 \\
\hline Speed-based & $50.3 \pm 6.1$ & $59.0 \pm 6.5^{*}$ & 1.39 & 2.39 to -0.23 \\
\hline \multicolumn{5}{|c|}{$V_{\text {IFT }}$ speed $\left(\mathrm{km} \cdot \mathrm{h}^{-1}\right)$} \\
\hline HR-based & $12.0 \pm 3.5$ & $13.6 \pm 3.0^{*}$ & 0.49 & 1.46 to -0.53 \\
\hline Speed-based & $12.7 \pm 3.5$ & $16.3 \pm 3.7^{*}$ & 1.01 & 1.99 to -0.08 \\
\hline \multicolumn{5}{|l|}{$\mathrm{V}_{\text {IFT }}$ time (min) } \\
\hline HR-based & $7.1 \pm 0.5$ & $9.0 \pm 0.5 *$ & 3.89 & 5.20 to 2.07 \\
\hline Speed-based & $7.6 \pm 0.5$ & $13.5 \pm 0.7 *$ & 4.3 & 6.45 to 1.27 \\
\hline
\end{tabular}

${ }^{*}$ denotes significant differences between baseline and post training values $(p \leq 0.05) ;{ }^{\dagger}$ denotes significant differences between the experimental groups at post training $(p \leq 0.05)$.

\section{Discussion}

Strength and conditioning coaches, to improve fitness level in soccer players, have extensively used HIIT. HIIT may induce both central and peripheral physiological adaptations [8]. However, to the authors' knowledge the comparison of HR-based and speed-based intensity prescription during HIIT have never been examined in female soccer players. Therefore, the purpose of this study was to compare the effects of HR-based and speed-based intensity prescriptions for HIIT on aerobic and anaerobic capacity of female soccer players. Main results indicate that both intensity prescription methods are practical and effective to improve aerobic and anaerobic fitness variables in female soccer players (except maximal power for both groups, and fatigue index and average power for the HR-based HIIT group). However, speed-based intensity prescription induced greater improvements in power (i.e., average and minimal) and fatigue resistance compared to the HR-based prescription. In line with current findings, a number of studies have shown that HIT improve $\mathrm{VO}_{2}$ max and anaerobic capacities [16-18,23-25]. For example, Sperlich et al. [26] and Helgerud et al. [1] reported 7 to 11\% improvements in $\mathrm{VO}_{2}$ max after 5 to 8 weeks of HIIT in soccer players. HIIT may induce large adaptive responses by virtue of recruiting a broader population of muscle fibers and enhance cardiorespiratory signaling, resulting in $\mathrm{VO}_{2}$ max and anaerobic capacity gains $[15,25,27]$. There are several mechanisms to enhance $\mathrm{VO}_{2}$ max after HIIT including increases in muscle oxidation and buffering capacities, enhancements of PGC- $1 \alpha$, which plays an important role in mitochondrial gene transcription and other biochemical changes [26-29].

Regarding the important role of power and fatigue index during soccer games, both HR-based and speed-based HIIT prescription methods induced meaningful improvements in power-related performance and fatigue index in soccer; however, no previous studies reported these variables in female soccer players following HIIT. During cycling sprint interval training (SIT), Burgomaster et al. [30] reported that 6 weeks SIT induced 17\% improvements in power output. 
In addition, Zieman et al. [31] examined the effects of $6 \times 90 \mathrm{~s}$ SIT with $80 \% \mathrm{VO}_{2}$ max on power of physically active men and found significant increases. The possible mechanisms for the enhancement of anaerobic variables after HIIT could be the involvement of ATP-PC and anaerobic glycolis systems during periods of trials that involve repeated high-intensity sprints with relatively short recovery intervals, resulting in anaerobic enzyme adaptations [26]. Based on the findings of the present study, it appears that speed-based HIIT induced greater efficiency compared to HR-based (Hoff approach) methods in aerobic and anaerobic adaptation tests. The greater adaptive responses by VIFT-based HIIT vs. Hoff may be related to better regulation of running intensity in the latter, including the use of perceived exertion during training. Alternatively, the inability of $\mathrm{HR}$ to determine their association with metabolic demands and to inform running intensities above $\mathrm{vVO}_{2} \max [17,18]$ may also help to explain the results from this study. However, more studies are necessary to determine the influence of each variable and also determine role of each variable to enhance training adaptation following HIIT.

\section{Conclusions}

This is the first study that examined the effects of HR-based and speed-based intensity prescription for HIIT on aerobic and anaerobic capacity of female soccer players. The results of this study showed that both intensity prescription methods are practical and effective for improving aerobic and anaerobic fitness. However, speed-based intensity prescription induced greater improvements in power and fatigue resistance compared to HR-based prescription.

Acknowledgments: Authors kindly thank players and officials Ayandehsazan-e-Mihan soccer team.

Author Contributions: H.A. conceived and designed the experiments; A.K., S.T. and A.E. performed the experiments; A.K. analyzed the data; A.O. contributed materials and analysis tools; H.A. and A.E. wrote the paper; A.A. and R.R.-C. rewrote and revised the paper.

Conflicts of Interest: The authors declare no conflict of interest.

\section{References}

1. Helgerud, J.; Engen, L.C.; Wisloff, U.; Hoff, J. Aerobic endurance training improves soccer performance. Med. Sci. Sports Exerc. 2001, 33, 1925-1931. [CrossRef] [PubMed]

2. Bangsbo, J. The physiology of soccer-With special reference to intense intermittent exercise. Acta Physiol. Scand. 1993, 619, 1-55.

3. Bangsbo, J.; Nørregaard, L.; Thorsoe, F. Activity profile of competition soccer. Can. J. Sport Sci. 1991, 16, 110-116. [PubMed]

4. Mohr, M.; Krustrup, P.; Bangsbo, J. Match performance of high-standard soccer players with special reference to development of fatigue. J. Sports Sci. 2003, 21, 519-528. [CrossRef] [PubMed]

5. Withers, R.T.; Maricic, Z.W.; Wasilewski, S.; Kelly, L. Match analysis of Australian professional soccer players. J. Hum. Mov. Stud. 1982, 8, 159-176.

6. Reilly, T. Physiological aspects of soccer. Biol. Sport 1994, 11, 3-20.

7. Helgerud, J. Maximal oxygen uptake, anaerobic threshold and running economy in women and men with similar performances level in marathons. Eur. J. Appl. Physiol. Occup. Physiol. 1994, 68, 155-161. [CrossRef] [PubMed]

8. Laursen, P.B.; Jenkins, D.G. The scientific basis for high-intensity interval training. Sports Med. 2002, 32, 53-73. [CrossRef] [PubMed]

9. Kessler, H.S.; Sisson, S.B.; Short, K.R. The potential for high-intensity interval training to reduce cardiometabolic dis-ease risk. Sports Med. 2012, 42, 489-509. [CrossRef] [PubMed]

10. Salmon, J.; Owen, N.; Crawford, D.; Bauman, A.; Sallis, J.F. Physical activity and sedentary behavior: A population-based study of barriers, enjoyment and preference. Health Psychol. 2003, 22, 178-188. [CrossRef] [PubMed]

11. MacDougall, J.D.; Hicks, A.L.; MacDonald, J.R.; McKelvie, R.S.; Green, H.J.; Smith, K.M. Muscle performance and enzymatic adaptations to sprint interval training. J. Appl. Physiol. 1998, 84, 2138-2142. [PubMed] 
12. Wisløff, U.; Castagna, C.; Helgerud, J.; Jones, R.; Hoff, J. Strong correlation of maximal squat strength with sprint performance and vertical jump height in elite soccer players. Br. J. Sports Med. 2004, 38, 285-288. [CrossRef] [PubMed]

13. Hawley, J.; Myburgh, K.H.; Noakes, T.D.; Dennis, S.C. Training techniques to improve fatigue resistance and enhance endurance performance. J. Sports Sci. 1997, 15, 325-333. [CrossRef] [PubMed]

14. Kitamura, K.; Jorgensen, C.R.; Gobel, F.L.; Taylor, H.L.; Wang, Y. Hemodynamic correlates of myocardial oxygen consumption during upright exercise. J. Appl. Physiol. 1972, 32, 516-522. [PubMed]

15. Karp, J.R. Interval Training for the Fitness Professional. Strength Cond. J. 2000, 22, 64. [CrossRef]

16. Tanisho, K.; Hirakawa, K. Training effects on endurance capacity in maximal intermittent exercise: comparison between continuous and interval training. J. Strength Cond. Res. 2009, 23, 2405-2410. [CrossRef] [PubMed]

17. Buchheit, M.; Laursen, P.B. High-intensity interval training, solutions to the programming puzzle-part I. Sports Med. 2013, 43, 313-338. [CrossRef] [PubMed]

18. Buchheit, M. The 30-15 intermittent fitness test: accuracy for individualizing interval training of young intermittent sport players. J. Strength Cond. Res. 2008, 22, 365-374. [CrossRef] [PubMed]

19. Hoff, J.; Wisløff, U.; Engen, L.C.; Kemi, O.J.; Helgerud, J. Soccer specific aerobic endurance training. Br. J. Sports Med. 2002, 36, 218-221. [CrossRef] [PubMed]

20. Rabbani, A.; Buchheit, M. Heart Rate- Versus Speed-based High-intensity interval Training in Young Soccer Players. In Proceedings of the 4th World Conference on Science and Soccer, Portland, OR, USA, 5-7 June 2014.

21. Buchheit, $M$. The 30-15 intermittent fitness Test: A new intermittent running field test for intermittent sport players. Football Sci. Net 2005, 87, 27-34.

22. Hopkins, W.G.; Marshall, S.W.; Batterham, A.M.; Hanin, J. Progressive statistics for studies in sports medicine and exercise science. Med. Sci. Sports Exerc. 2009, 41, 3-13. [CrossRef] [PubMed]

23. Bencke, J.; Damsgaard, R.; Saekmose, A.; Jørgensen, P.; Jørgensen, K.; Klausen, K. Anaerobic power and muscle strength characteristics of 11 years old elite and non-elite boys and girls from gymnastics, team handball, tennis and swimming. Scand. J. Med. Sci. Sports 2002, 12, 171-178. [CrossRef] [PubMed]

24. Saltin, B. Hemodynamic adaptations to exercise. Am. J. Cardiol. 1985, 55, D42-D47. [CrossRef]

25. Gharah, D.N.; Kordi, M.R.; Gaeini, A.A. The effect of 4-week high intensity interval aerobic training $\mathrm{VO}_{2} \max$, TMAX, $\mathrm{vVO}_{2}$ max of Iranian club soccer players. Biol. Exerc. Sci. 2014, 17, 47-57.

26. Sperlich, B.; De Marées, M.; Koehler, K.; Linville, J.; Holmberg, H.C.; Mester, J. Effects of 5 weeks of high-intensity interval training vs. volume training in 14-year-old soccer players. J. Strength Cond. Res. 2011, 25, 1271-1278. [CrossRef] [PubMed]

27. Gilllen, J.B.; Percival, M.E.; Skelly, S.E.; Martin, B.J.; Tan, R.B.; Tar-nopolsky, M.A.; Gibala, M.J. Three minutes of all-out intermittent exercise per week increases skeletal muscle oxidative capacity and improves cardiometabolic health. PLOS ONE 2010, 9, e111489.

28. Gollnick, P.D.; Piehl, K.; Saltin, B. Selective glycogen deple-tion pattern in human muscle fibers after exercise of varying intensity and at varying pedaling rates. J. Physiol. 1974, 241, 45-57. [CrossRef] [PubMed]

29. McLaren, D.; Morton, J. Biochemistry for Sport and Exercise Metabolism, 1st ed.; John Willy \& Sons: Hoboken, NJ, USA, 2012.

30. Burgomaster, K.A.; Howarth, K.R.; Phillips, S.M.; Rakobowchuk, M.; Macdonald, M.J.; McGee, S.L.; Gibala, M.J. Similar metabolic adaptations during exercise after low volume sprint interval and traditional endurance training in humans. J. Physiol. 2008, 586, 151-160. [CrossRef] [PubMed]

31. Ziemann, E.; Grzywacz, T.; Łuszczyk, M.; Laskowski, R.; Olek, R.A.; Gibson, A.L. Aerobic and anaerobic changes with high-intensity interval training in active college-aged men. J. Strength Cond. Res. 2011, 25, 1104-1112. [CrossRef] [PubMed]

(C) 2017 by the authors. Licensee MDPI, Basel, Switzerland. This article is an open access article distributed under the terms and conditions of the Creative Commons Attribution (CC BY) license (http:// creativecommons.org/licenses/by/4.0/). 